\title{
СРАВНИТЕЛЬНАЯ ОЦЕНКА
}

МУЛЬЧИРУЮЩИХ МАТЕРИАЛОВ НА

ПОСЕВАХ ДЫНИ В ЦЕНТРАЛЬНОЙ ЗОНЕ

КРАСНОДАРСКОГО КРАЯ

\section{COMPARATIVE EVALUATION OF MULCHING MATERIALS ON MELON SOWING IN THE CENTRAL ZONE OF KRASNODAR REGION}

\begin{abstract}
В.Э. Лазько, кандидат сельскохозяйственных наук, О.В. Якимова
\end{abstract}

ФГБНУ «ФНЦ риса»
V.E. Lazko, Ph.D. in agriculture, O.V. Yakimova

Federal Research Center for Rice
На летних посевах дыни сорта Стрельчанка изучено использование вторичной целлюлозы для мульчирования почвы. Получены результаты по температурному балансу на поверхности почвы и в зоне залегания основной массы корней. Отмечена эффективность применения мульчирующего материала в сглаживании температурных колебаний, защите корневой системы растений от перегрева и создании благоприятных условий для увлажнения почвы. Мульча из вторичной целлюлозы препятствовала испарению поливной влаги и обеспечивала подавление роста сорняков, исключая необходимость проведения прополки в рядках. Анализ полученных результатов показал достоверное увеличение урожайности плодов дыни сорта Стрельчанка на 0,93 т/га $(+15,9 \%)$ в сравнении с контрольным вариантом, на котором применяли стандартную технологию. Применение полимерной биоразрушаемой пленки, изготовленной на основе полимолочной кислоты (PLA) и компаунда Ecoflex фирмы BASF, не обеспечило существенного преимущества во времени появления всходов, однако по дружности всходов этот вариант превосходил контроль на 14-17\%. Мульчирование способствовало увеличению накопления сухих растворимых веществ в мякоти плодов дыни. Для снижения расхода вторичной целлюлозы и создания равномерного мульчирующего слоя необходимо тщательное выравнивание почвы. К уборке биоразлагаемая полимерная пленка значительно потеряла пластичность и легко разрушалась. После демонтажа капельных лент поливной системы на опытных участках посевов дыни была проведена механизированная обработка почвы - дискование и вспашка. Остатки мульчирующего материала не загрязняли почву, не цеплялись и не наматывались на рабочие органы сельскохозяйственных орудий, не снижая качество проводимых агромероприятий.
The use of recycled cellulose for soil mulching was studied on summer crops of the Strelchanka variety. The results were obtained on the temperature balance on the soil surface and in the zone of occurrence of the main mass of roots. The effectiveness of the use of mulching material in smoothing temperature fluctuations, protecting the root system of plants from overheating and creating favorable conditions for soil moisture is noted. Recycled cellulose mulch resisted evaporation of irrigation moisture and provided suppression of weed growth, eliminating the need for weeding in rows. The analysis of the results obtained showed a significant increase in the yield of fruits of the Strelchanka variety by $0.93 \mathrm{t} / \mathrm{ha}(+15.9 \%)$ in comparison with the control option, which used the standard technology. The use of a polymeric biodegradable film made on the basis of polylactic acid (PLA) and the Ecoflex compound from BASF did not provide a significant advantage in the time of emergence of seedlings, however, in terms of germination, this option exceeded the control by $14-17 \%$. Mulching increased the accumulation of dry soluble substances in the melon fruit pulp. To reduce the consumption of recycled cellulose and create a uniform mulch layer, careful leveling of the soil is necessary. By cleaning, the biodegradable polymer film has significantly lost its plasticity and easily disintegrated. After dismantling the drip tapes of the irrigation system, mechanized soil cultivation was carried out on the experimental plots of melon crops - disking and plowing. The remains of the mulching material did not pollute the soil, did not cling to and wrap around the working bodies of agricultural implements, without reducing the quality of the agricultural activities.
Ключевые слова: мульчирующий материал, биоразрушаемая пленка, вторичная целлюлоза, дыня, температура, урожайность.
Key words: mulching material, biodegradable film, recycled cellulose, melon, temperature, yield. 
Введение. Температурный режим верхнего слоя почвы формируется под воздействием трансформации и перераспределения солнечной энергии. При нагревании поверхности происходит теплоотдача в почву. Интенсивность теплообмена зависит от теплофизических характеристик почвы и состояния ее поверхности (влажности, микрорельефа, укрытия мульчирующим материалом и др.) Некоторая часть энергии уходит на тепловое излучение поверхности почвы и затрачивается на испарение влаги $[3,8]$.

Мульчирование почвы в открытом грунте, при выращивании овощных культур, является эффективным агротехнологическим приемом, способствующим созданию более благоприятного тепловлажностного режима почвы и предпочвенного слоя воздуха, улучшению физических свойств почвы и усилению биохимических процессов в ней. Одновременно с этим мульча угнетает и ограничивает рост и развитие сорняков.

Мульчирование почвы как агротехнический прием применяют давно. В качестве мульчирующего материала используют солому, торф, сухие листья, опилки, навоз, специальную мульчбумагу, синтетические пленки и другие материалы. Покрытие поверхности почвы мульчей позволяет, в зависимости от ее физико-механических свойств, разнообразно воздействовать на весь комплекс факторов, определяющих физические условия в почве. Подбирая мульчирующие материалы с определенными физико-механическими и оптическими характеристиками, можно активно влиять на режим температуры и влажности почвы, уменьшать или аккумулировать величину солнечной радиации [8]. В последнее время производители овощной продукции используют полимерную пленку, основным недостатком которой является значительный период ее разложения и, как следствие, засорение полей. Выполнение послеуборочных мероприятий по удалению пленки с участков затруднено из-за растительных остатков. Пленка цепляется и наматывается на рабочие органы сельскохозяйственных орудий, снижая качество проводимых агромероприятий [2]. Создаются и предлагаются к применению новые мульчирующие материалы, такие как полимерная биоразлагаемая пленка фирмы BASF и вторичная целлюлоза. Эти материалы необходимо апробировать и разработать регламент их применения на овощных культурах. Цель исследований - определить эффективность применения мульчирования почвы полимерной биоразлагаемой пленкой фирмы BASF и вторичной целлюлозой на посевах дыни.

Материалы и методы. Производственный опыт проводили в 2020 г. на селекционно-семеноводческом участке овощебахчевых культур ФГБНУ «ФНЦ риса» на летнем посеве дыни раннеспелого сорта Стрельчанка, с периодом вегетации 55-58 дней от всходов до уборки. Учетная площадь делянки составляла $10 \mathrm{~m}^{2}$, повторность в опыте 3-х кратная. Расположение вариантов рендомизированное. Площадь питания одного растения - $2 \mathrm{M}^{2}$ $(2,0 \times 1,0)$. Посев осуществлен семенами категории ОС, вручную 15 июля, на участке после уборки чеснока. На делянку высевалось 5 г семян. Густота посева из расчета 5 тыс. штук растений на гектар. Минеральное удобрение нитроаммофоску $\left(\mathrm{N}_{16} \mathrm{P}_{16} \mathrm{~K}_{16}\right)$ вносили до посева перед фрезерованием почвы. Норма внесения минеральных удобрений $\mathrm{N}_{60} \mathrm{P}_{60} \mathrm{~K}_{60}$ кг д. В./га (по 375 кг/ га физических туков). Для обеспечения всходов влагой при летнем посеве укладывали капельную ленту с расстоянием между эмиттерами 35 см.

Для мульчирования почвы использовали полимерную биоразлагаемую пленку, изготовленную на основе полимолочной кислоты (PLA) и компаунда Ecoflex, которая к концу сезона вегетации, благодаря действию ультрафиолетовых лучей, влаги и активной деятельности почвенных микроорганизмов, теряет свою прочность и пластичность и разрушается на почве. Биоразлагаемую пленку метровой ширины и толщиной 10 микрон раскатывали на поверхность почвы и крепили, присыпая почвой в бороздах. Перфорацию пленки в местах высева семян и посев делали вручную [6]. Посеянные семена присыпали почвой. Второй мульчиру- ющий материал - вторичная целлюлоза, которая состоит на 70\% из измельченной целлюлозы серо-белого цвета и $30 \%$ кальция с $\mathrm{pH}-7,6$. Насыпная

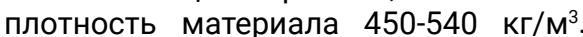
Период полного разложения вторичной целлюлозы 11-15 месяцев. Через 5 дней после посева, когда появились всходы, мульчирующий материал наносили на почву по центру посевного ряда. Ширина мульчирующей полосы 0,5 м и толщина слоя 5 см. Растения в момент нанесения мульчи закрывали полиэтиленовыми стаканами.

При закладке опытов и проведении исследований использовали методику полевого опыта в овощеводстве [1, 5 7]. Агротехнику выращивания бахчевых культур на опытных участках выполняли в соответствии с разработанными рекомендациями в отделе овощекартофелеводства ФГБНу «ВНИИ риса» $[1,9,10,11]$. Статистическая обработка полученных данных проведена согласно методическим рекомендациям A.X. Шеуджена $[4,12]$.

Результаты и обсуждение. Погодные условия периода вегетации бахчевых культур в 2020 году были экстремальными. Они имели скачкообразный характер: аномально высокие температуры в июне без выпадения осадков сменились умеренной температурой в июле с количеством осадков, близким к среднегодовым значениям. В конце второй декады июля (20.07.2020) сильный град со шквалистым ветром (25 м/с) нанес значительные механические повреждения посевам и пленочному покрытию. Более $50 \%$ растений бахчевых культур имели

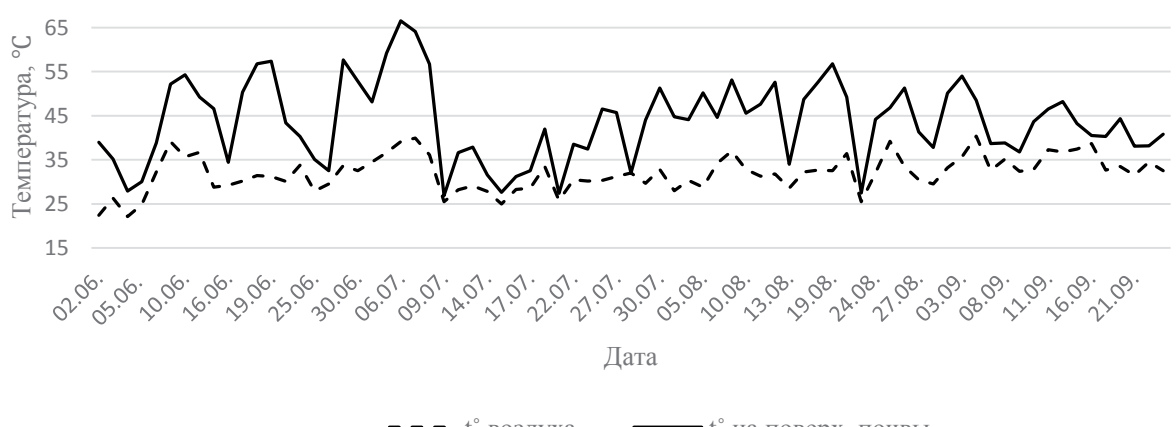

Рисунок 1 - Динамика температуры воздуха и поверхности почвы, 2020 год

Вторичная целлюлоза

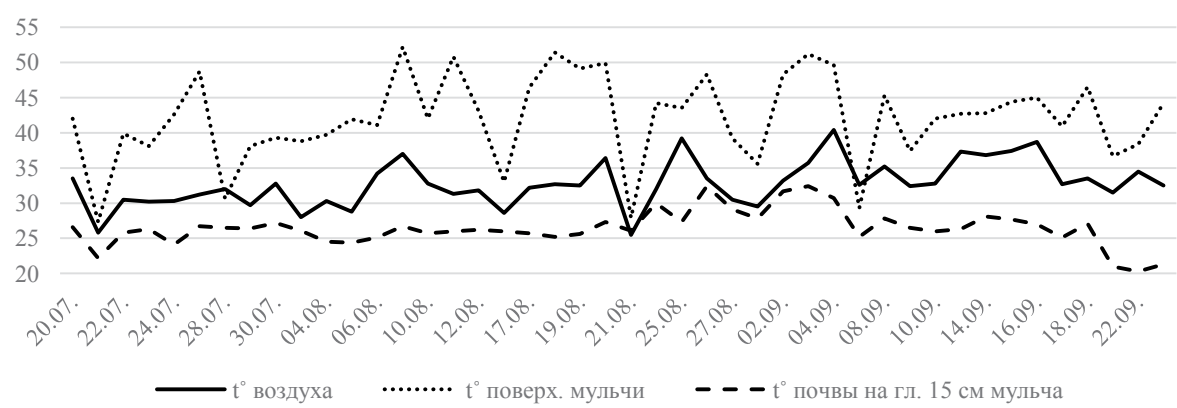

Рисунок 2 - Динамика температуры воздуха и почвы при использовании мульчирующего покрытия из вторичной целлюлозы 
механические повреждения или были уничтожены. Размер кристаллов льда доходил до 6-8 мм.

Результаты измерения температуры воздуха и почвы представлены на графиках (рисунки 1, 2, 3, 4). Наблюдения показали, что поверхность почвы нагревалась сильнее, чем поверхность вторичной целлюлозы, благодаря отражению света от серо-белой поверхности мульчирующего материала. В ясные безоблачные дни разница доходила до $10^{\circ} \mathrm{C}$, однако почва под мульчей на глубине 10 см всегда оставалась менее прогретой, разница доходила до $3,3^{\circ} \mathrm{C}$ и имела меньшую амплитуду колебаний температуры, так как значительная часть тепла отражалась от поверхности мульчирующего слоя. Мульчирующий экран защищал от перегрева зону размещения основной массы корней. За первый месяц периода вегетации под мульчей корневая система испытала меньше на $63^{\circ} \mathrm{C}$ температурную нагрузку. В июле среднемесячная температура почвы на глубине 10 см под мульчей $-25,8^{\circ} \mathrm{C}$, в контрольном варианте $-28,0^{\circ} \mathrm{C}$. В августе на корни воздействовало суммарного тепла на $49,6^{\circ} \mathrm{C}$ меньше. Среднемесячная температура в августе под мульчирующим слоем $-26,7^{\circ} \mathrm{C}$, в контрольном варианте - $29,0^{\circ} \mathrm{C}$. Мульча создавала более комфортный для корневой системы температурный режим и влагообеспеченность. Мульчирующий слой целлюлозы полностью подавлял рост сорняков, исключая прополку в рядках.

Наблюдения показали, что поверхность черной пленки из Еcovio фирмы BASF нагревалась сильнее, чем поверхность почвы. В среднем разница температур по месяцам составляла $4,3-5,8^{\circ} \mathrm{C}$. Однако почва на глубине $10 \mathrm{~cm}$ под мульчирующей пленкой оставалась на $0,1-1,0^{\circ} \mathrm{C}$ менее прогретой. Под чер-

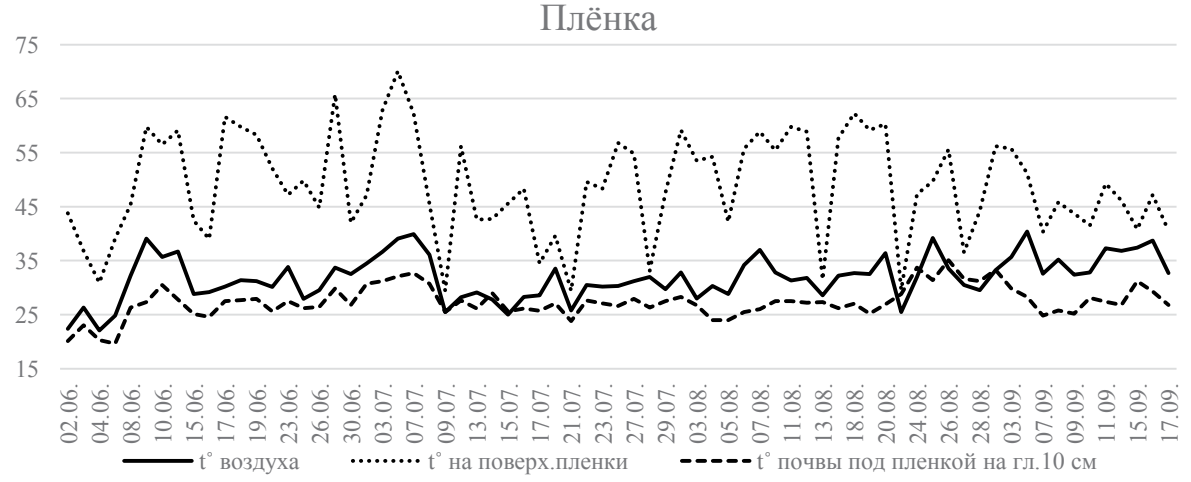

Рисунок 3 - Влияние мульчирования почвы черной полимерной пленкой фирмы BASF на динамику температуры воздуха и почвы

\section{Контроль}

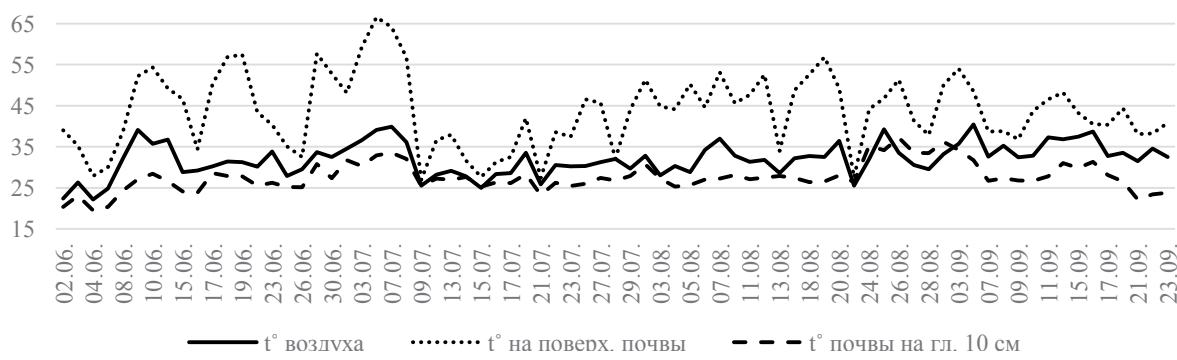

Рисунок 4 - Динамика температуры воздуха и почвы в контрольном варианте

ной биоразлагаемой пленкой фирмы BASF на корни в месяц воздействовало суммарного тепла на $16,6-18,3^{\circ} \mathrm{C}$ меньше, чем без мульчи. Черная биоразлагаемая пленка фирмы BASF исключала испарение поливной влаги с поверхности почвы, что существенно влияло на влагообеспеченность растений. Мульча из Ecovio, как и вторичная целлюлоза, полностью подавляла рост сорняков. Температурный баланс в по- чве под мульчирующей пленкой имел показатели хуже, чем под мульчирующим слоем из вторичной целлюлозы но оставался более благоприятным в сравнении с вариантом без мульчирования. Вероятнее всего, разница была по причине механического повреждения пленки градом.

Создание оптимальных температурных условий в почве на глубине корнеобитаемого слоя благодаря использова-

Таблица 1 - Влияние мульчирования почвы на биометрические и биохимические параметры плодов дыни сорта Стрельчанка

\begin{tabular}{|c|c|c|c|c|c|c|}
\hline \multirow[t]{2}{*}{ Вариант } & \multicolumn{2}{|c|}{$\begin{array}{c}\text { Кол-во плодов на одном } \\
\text { растении, шт. }\end{array}$} & \multicolumn{2}{|c|}{ Масса плода, кг } & \multicolumn{2}{|c|}{ CPB, \% } \\
\hline & «min-max» & среднее & «min-max» & средняя & «min-max» & среднее \\
\hline Целлюлоза & $1,6-2,9$ & 2,4 & $0,31-2,05$ & 1,44 & $8,3-12,0$ & 11,0 \\
\hline Пленка & $1,9-2,7$ & 2,3 & $0,33-1,96$ & 1,28 & $8,5-11,8$ & 10,3 \\
\hline Контроль & $1,7-2,4$ & 2,0 & $0,29-1,64$ & 0,94 & $7,5-11,5$ & 9,8 \\
\hline \multicolumn{5}{|c|}{$\begin{array}{l}\text { Для количества плодов } F_{\text {факт. }} 15,04>F_{05} 5,14 \\
\text { Для массы плодов } F_{\text {факт. }} 39,98>F_{05} 4,07 \\
\text { Для CPB } F_{\text {факт }} 35,62>F_{05} 4,07\end{array}$} & \multicolumn{2}{|c|}{$\begin{array}{l}\mathrm{HCP}_{05}=0,2 \text { штуки } \\
\mathrm{HCP}_{05}=0,15 \text { кг } \\
\mathrm{HCP}_{05}=0,5 \%\end{array}$} \\
\hline
\end{tabular}

Таблица 2 - Влияние мульчирования почвы на урожайность дыни сорта Стрельчанка

\begin{tabular}{|c|c|c|c|}
\hline Вариант & Урожайность, т/га & \multicolumn{2}{|c|}{ т/га к контролю } \\
\hline Целлюлоза & 8,07 & $+2,24$ & $+38,4$ \\
\hline Пленка & 6,76 & $+0,93$ \\
\hline Контроль & 5,83 & - \\
\hline Для урожайности $\mathrm{F}_{\text {факт. }} 7,11>\mathrm{F}_{05} 5,14$ & $\mathrm{HCP}_{05}=0,78 \mathrm{~T} /$ га & \\
\hline
\end{tabular}


нию мульчирования, в конечном счете, привело к увеличению продуктивности дыни сорта Стрельчанка.

Под мульчирующим слоем вторичной целлюлозы корневая система растений дыни меньше подвергалась перегреву. Мульча целлюлозой способствовала сохранению влаги в почве и сдерживала развитие сорняков. Несмотря на значительные повреждения градом, созданные условия способствовали формированию большего количества плодов на одном растении и с большей массой (таблица 1). В итоге урожайность при использовании мульчирующего материала составила 8,07т/га и превысила контроль на 38,4\% (таблица 2). Следует отметить, что применение мульчирования целлюлозой способствовало большему накоплению сухих растворимых веществ (СРВ) в мякоти плодов. После уборки и удаления капельной ленты мульчирующий слой вторичной целлюлозы не создавал препятствий при обработке почвы.

Применение черной мульчирующей пленки фирмы BASF не обеспечило существенного преимущества во времени появления всходов, однако по их дружности этот вариант превосходил контроль на 14-17\%. Мульчирование почвы пленкой также обеспечило получение на одном растении большего количества плодов и с большей массой, чем в контроле, но уступало показателям использования вторичной целлюлозы (таблицы 1, 2). Урожайность была выше, чем в контроле, на 15,9\%. Следует отметить, что содержание сухих растворимых веществ (СРВ) в мякоти плодов при этом уступало варианту с использованием вторичной целлюлозы на 6,8\%, но превышало контроль на 5,1\%. К уборке биоразлагаемая полимерная пленка значительно потеряла пластичность и легко разрушалась. После демонтажа капельных лент поливной системы на опытных участках посевов дыни была проведена механизированная обработка почвы - дискование и вспашка. Остатки мульчирующего материала не загрязняли почву, не цеплялись и не наматывались на рабочие органы сельскохозяйственных орудий, не снижая качество проводимых агромероприятий.

Заключение. Мульчирование почвы вторичной целлюлозой и полимерной биоразрушаемой пленкой, изготовленной на основе полимолочной кислоты (PLA) и компаунда Ecoflex фирмы BASF, защищает корневую систему от перегрева и сглаживает колебания температуры в почве. Оно препятствует испарению влаги и подавляет рост сорняков, исключая необходимость проведения прополки в рядках. Применение вторичной целлюлозы создало оптимальные условия для корневой системы дыни, вследствие чего на растении сформировалось больше плодов большей массы. В итоге был собран урожай на 2,24 т/га больше, чем в контрольном варианте. Использование мульчирующей полимерной биоразрушаемой пленки из-за повреждения градом способствовало повышению урожайности на $15,9 \%$ в сравнении с контролем. После завершения уборки и удаления капельной ленты вторичная целлюлоза и полимерная пленка не создавали препятствий для применения механизированной обработки почвы.

\section{Библиографический список}

1. Варивода, О.П. Технология выращивания дыни / О.П. Варивода // Вестник АПК Волгоградской области. - 2006. - № 1 (257). - С. 24-25.

2. Гиш, Р.А. Овощеводство юга России: учебник / Р.А. Гиш, Г.С. Гикало // Краснодар: ЭДВИ. - 2012. - 632 с.

3. Гончарук, Н.С. Полимеры в овощеводстве / Н.С. Гончарук // М.: Колос. - 1971. - 264 с.

4. Дзюба, В.А. Многофакторные опыты и методы биометрического анализа экспериментальных данных / В.А. Дзюба // Методическое пособие. - Краснодар, 2007. - 76 с.

5. Колебошина, Т.Г. Особенности агротехнологии бахчевых культур в зоне рискованного земледелия РФ / Т.Г. Колебошина, Ю.А Быковский // Труды Кубанского аграрного университета, 2016. - №3 (60). - С. 123.

6. Королева, С.В. Применение мульчирующей черной полимерной биоразрушаемой пленки фирмы BASF на овощебах чевых культурах / С.В. Королева, В.Э. Лазько, И.В. Козлова, О.В. Якимова [и др.] // Рисоводство. - Краснодар, 2020. - №1 (46). - С. 71-77.

7. Литвинов, С.С. Методика опытного дела в овощеводстве. - М., 2011. - 648 с.

8. Микаелян, Г.А. Основы оптимального проектирования производственных процессов в овощеводстве / Г.А. Микаелян Р.Д. Нурметов // М.: ФГНУ «Росинформагротех», 2005. - 640 с.

9. Семеринова, А.Г. Агротехника бахчевых культур / А.Г. Семеринова. // М.: Россельхозиздат, 1978. - С.3.

10. Тимофеев, Н.Н. Селекция и семеноводство овощных культур / Н.Н. Тимофеев, А.А. Волкова, С.Т. Чижов // М.: Колос. - 1972. - С.3.

11. Цыбулевский, Н.И. Бахчевые культуры (рекомендации) / Н.И. Цыбулевский, Е.М. Кулиш, Л.А. Шевченко // Краснодар, 2009. - 34 с

12. Шеуджен, А.Х. Агрохимические основы применения удобрений / А.Х. Шеуджен, Т.Н. Бондарева, С.В. Кизинек // Майкоп: Полиграф-Юг, 2013. - 271 с.

\section{Дополнительные сведения об авторах:}

Виктор Эдуардович Лазько, ведущий научный сотрудник лаборатории бахчевых и луковых культур, lazko62@mail.ru,

Ольга Владимировна Якимова, научный сотрудник лаборатории бахчевых и луковых культур, belyaeva12092013@yandex.ru

\section{Bibliographic list}

1. Varivoda, O.P. Melon cultivation technology / O.P. Varivoda // Bulletin of the agro-industrial complex of the Volgograd region. 2006. - No. 1 (257). - Pp. 24-25.

2. Guiche, R.A. Vegetable growing of the south of Russia: textbook / R.A. Guiche, G.S. Gikalo // Krasnodar: EDVI. - 2012. $-632 \mathrm{p}$.

3. Goncharuk, N.S. Polymers in vegetable growing / N.S. Honcharuk // M.: Kolos. - 1971. - 264 p.

4. Dziuba, V.A. Multifactorial experiments and methods of biometric analysis of experimental data / V.A. Dzyuba // Methodological manual // Krasnodar, 2007. - 76 p.

5. Koleboshina, T.G. Features of agrotechnology of melons and gourds in the zone of risky agriculture of the Russian Federation / T.G. Koleboshina, Yu.A. Bykovsky // Proceedings of the Kuban Agrarian University, 2016. - No. 3 (60). - P. 123.

6. Koroleva, S.V. Application of BASF mulching black polymer biodegradable film on vegetable and melon crops / S.V. Koroleva, V.E. Lazko, I. V. Kozlova, O. V. Yakimova [et al.] // Rice growing. Krasnodar, 2020. - No. 1 (46). - Pp. 71-77.

7. Litvinov, S. S. Experimental methodology in vegetable growing. - M., 2011. - $648 \mathrm{p}$.

8. Mikaelyan, G.A. Fundamentals of optimal design of production processes in vegetable growing / G.A. Mikaelyan, R.D. Nurmetov. - M.: «Rosinformagrotech». - 2005. - 640 p.

9. Semerinova, A.G. Agrotechnics of melons and gourds / A.G. Semerinova // M.: Rosselkhozizdat, 1978. - P. 3.

10. Timofeev, N.N. Selection and seed production of vegetable crops / N.N. Timofeev, A.A. Volkova, S.T. Chizhov // M.: Kolos. -1972 . - P. 3.

11. Tsybulevsky, N.I. Melons cultures (recommendations) / N.I. Tsybulevsky, E.M. Kulish, L.A. Shevchenko // Krasnodar, 2009. $34 \mathrm{p}$.

12. Sheujen, A.Kh. Agrochemical basis for the application of fertilizers / A.Kh. Sheujen, T.N. Bondareva, S.V. Kizinek // Maykop: Polygraph-Yug, 2013. - $271 \mathrm{p}$

\section{Additional information about the authors:}

Victor Eduardovich Lazko, leading researcher of the laboratory of melon and onion crops, lazko62@mail.ru,

Olga Vladimirovna Yakimova, researcher of the laboratory of melon and onion crops, belyaeva12092013@yandex.ru 